\title{
"NÃO FAÇO A MENOR IDEIA": COMO LIDAR COM PERGUNTAS INUSITADAS DOS ESTUDANTES
}

\author{
"I have no idea": how to deal with unusual student questions \\ "No tengo ideia": cómo lidiar con las preguntas inusitadas de los estudiantes
}

\begin{abstract}
Marcela Arantes Meirelles ${ }^{1}$
Cristhiane Carneiro Cunha Flôr ${ }^{2}$

Resumo

A sala de aula é um espaço propício para o estímulo das perguntas e por isto devemos pensar no papel das mesmas na construção de conhecimentos científicos. Portanto, este trabalho pretende relatar uma atividade realizada na Educação Básica a partir de perguntas inusitadas feita pelos estudantes de forma a estimular a criatividade, o dinamismo e a colaboração. Percebemos que o estímulo às perguntas durante as aulas têm se mostrado muito promissor, pois auxilia na aprendizagem, na busca por novas informações e no debate de ideias; além de criar um ambiente onde os estudantes se sintam à vontade para perguntar e expor suas dúvidas.
\end{abstract}

PALAVRAS-CHAVE: Perguntas inusitadas. Questionamentos. Dúvidas dos estudantes.

\begin{abstract}
The classroom is a propitious space for the stimulation of questions and for this we should think about their role in the construction of scientific knowledge. Therefore, this article intends to report an activity carried out in High School based on unusual questions asked by students in order to stimulate creativity, dynamism and collaboration. We have noticed that the stimulation of the questions during the classes has been very promising, as it helps in learning, in the search for new information and in the debate of ideas; besides creating an environment where students feel free to ask and share their doubts.
\end{abstract}

KEYWORDS: Unusual questions. Questionings. Students doubts.

\section{Resumen}

La clase es un espacio propicio para el estímulo de las preguntas y por eso debemos pensar en el papel de las mismas en la construcción de conocimientos científicos. Por lo tanto, este trabajo pretende relatar una actividad realizada en la Educación Secundaria a partir de preguntas inusitadas de los estudiantes para estimular la creatividad, el dinamismo y la colaboración. Se percibe que el estímulo a las preguntas durante las clases se ha mostrado muy prometedor, pues auxilia en el aprendizaje, en la búsqueda de nuevas informaciones y en el debate de ideas; además de crear un ambiente donde los estudiantes se sientan cómodos para preguntar y exponer sus dudas.

PALABRAS CLAVE: Preguntas inusitadas. Cuestionamientos. Preguntas de los estudiantes.

\footnotetext{
${ }^{1}$ Mestranda em Educação pelo Programa de Pós-graduação em Educação da Universidade Federal de Juiz de Fora (UFJF). Professora efetiva da rede estadual de Educação Básica de Minas Gerais. Universidade Federal de Juiz de Fora. Telefone: (32) 99100-5890. E-mail: marcela.a.meirelles@ hotmail.com

${ }^{2}$ Doutora em Educação Cientifica e Tecnológica pela Universidade Federal de Santa Catarina (UFSC). Professora adjunta na Faculdade de Educação e do Programa de Pós-graduação em Educação da Universidade Federal de Juiz de Fora (UFJF). Telefone: (32) 98883-6237. E-mail: cristhianeflor@ yahoo.com.br
} 


\section{INTRODUÇÃO}

Professor(a), por que o céu é azul? E o que é um buraco negro? Dá para fazer um acelerador de partículas?! Perguntas como essas são constantemente feita pelos estudantes numa aula de Ciências, de modo geral. Devemos refletir sobre como nós, professores, lidamos com essas perguntas. Será que é possível levar em consideração esses questionamentos dos estudantes sem que comprometa o planejamento do curso e, ao mesmo tempo, discuta conceitos científicos importantes?

Consideramos que a sala de aula é um locus rico na diversidade de situações vividas pelo professor. Estes lidam de diferentes formas mediante circunstâncias inusitadas. Concordamos com a ideia que, “[...] o professor tem de ser capaz de apreender intuitivamente as situações, articulando pensamento e ação e gerindo dinamicamente relações sociais; tem de ter autoconfiança e capacidade de improvisação perante situações novas" (PONTE et al., 1998, p. 3).

E uma situação muito corriqueira na vida do docente são as perguntas inusitadas que os estudantes fazem durante as aulas (muitas vezes, tão temidas pelos professores!). Em sua maior parte, são frutos da curiosidade, interesse e até mesmo da concepção prévia dos estudantes, mas em alguns casos podem ser questionamentos que de alguma forma enfrentam e testam o conhecimento que o professor possui.

$\mathrm{Na}$ infância, a curiosidade do estudante ainda é exacerbada, mas ao longo de sua vida ele vai deixando de questionar por falta de estímulo do professor, por conta de currículos cheios de respostas sem perguntas e por diversos outros fatores. É possível abolir toda a curiosidade ou entusiasmo do estudante a uma nova aprendizagem quando situações de ensino são regadas por emoções desagradáveis ou quando o professor faz um feedback negativo (ALMEIDA, 2002).

Porém, muitas destas perguntas não sabemos responder de imediato. "Quando o professor se depara com um imprevisto que não consegue resolver, sua forte tendência é retornar ao procedimento que lhe dá segurança porque já está embutido de uma previsibilidade" (SCARINCI e PACCA, 2007, p.11 e 12). Por isto, o presente trabalho aponta alguns caminhos para lidar com as perguntas inusitadas feitas pelos alunos, de forma a contribuir com a prática do professor, estimulando a curiosidade dos estudantes desde a mais tenra infância até o final do seu período escolar, deixando como herança para estes cidadãos a criticidade, a curiosidade e a criatividade.

Scarinci e Pacca (2007) ressaltam que, quando os professores permitem que os estudantes façam questionamentos, elaborem críticas, deem palpites e sugestões, eles deparam-se com as seguintes dificuldades: "[...] que fazer com as manifestações dos alunos sem perder a sequência da atividade e o objetivo final do conteúdo? Como reagir às perguntas inusitadas dos alunos, que não estavam exatamente previstas no planejamento do professor? (SCARINCI e PACCA, 2007, p.11)".

Além disso, quando nos abrimos às infinitas possibilidades do ato de questionar, nos deparamos com o fato de que nem sempre as respostas são únicas e verdadeiras, como muitas vezes é mostrado na construção do conhecimento em Química. As avaliações da área científica tendem a ser muito objetivas, no qual o questionamento deve gerar apenas uma resposta, como se a linguagem fosse realmente transparente e que basta elaborar uma pergunta que o outro entenderá exatamente o que você quer saber. 
Neste sentido, o referencial que utilizamos para compreender um pouco esse movimento é a Análise de Discurso de linha francesa e suas implicações na linguagem e formação de professores. Este referencial nos diz que a linguagem não é translúcida como um vidro de cristal, mas ela carrega uma grande quantidade de informações e relações que as caracterizam como opaca e inacabada. Dependendo da conjuntura em que o sujeito se encontra, é possível atribuir novos sentidos para um mesmo discurso.

A incompletude é a condição da linguagem: nem os sujeitos, nem os sentidos, logo, nem o discurso já estão prontos e acabados. Eles estão sempre se fazendo, havendo um trabalho contínuo, um movimento constante do simbólico e da história [...]. Daí dizermos que os sentidos e os sujeitos sempre podem ser outros (ORLANDI, 2005, p. 37).

Uma pergunta pode produzir diferentes sentidos para diferentes sujeitos em um determinado momento sócio-histórico, dependendo das condições de produção em que o discurso acontece. Essas condições de produção de discurso podem ser descritas a partir de alguns pontos:

As condições de produção, que constituem os discursos, funcionam de acordo com certos fatores. Um deles é o que chamamos relação de sentidos. Segundo essa noção, não há discurso que não se relacione com os outros. Em outras palavras, os sentidos resultam de relações: um discurso aponta para outros que o sustentam, assim como para dizeres futuros. Todo discurso é visto como um estado de processo discursivo mais amplo, contínuo. Não há, desse modo, começo absoluto nem ponto final para o discurso. Um dizer tem relação com outros dizeres realizados, imaginados ou possíveis (ORLANDI, 2005, p. 39).

No ensino de Ciências, de uma forma geral, não se considera que a linguagem é opaca e que os efeitos de sentido podem ser diversos para diferentes sujeitos. Podemos perceber tal fato, diante das avaliações nos diferentes níveis de ensino. Muitas vezes cobramos a fiel reprodução do conteúdo estabelecido nos currículos sem refletir sobre o papel avaliativo e formativo das provas e testes. Além disso, nos deparamos com o fato de ter que preparar o estudante para realizar diversas avaliações internas e externas, nas quais eles são cobrados a desenvolver respostas únicas e como se -no caso das ciências- a natureza fosse tão exata a ponto de só aceitar um tipo de resolução. Desta forma, a compreensão dos fundamentos e preceitos da ciência, frequentemente, é simplificada e substituída por uma infinidade de definições e fórmulas. Esperam-se respostas unívocas e exatas como se determinada pergunta só pudesse gerar um tipo de resposta e que, para isto, bastasse interpretar o enunciado que o estudante saberia responder prontamente, sem considerar que os efeitos de sentido de uma pergunta para um leitor são diferentes dos efeitos provocados em outro.

Contudo, à medida que práticas discursivas são incentivadas nas aulas, os estudantes vão se apropriando de novas formas de se expressar, adquirindo mais independência e confiança em suas ideias, além de atitudes mais científicas baseadas na atuação do professor (CANDELA, 1997). Dessa forma, é de fundamental importância perceber as relações discursivas que emergem da interação comunicativa entre estudante e professor e considerar a opacidade da linguagem e os diferentes efeitos de sentidos entre os interlocutores.

A comunicação é baseada, em muitos casos, no esquema emissor, mensagem $e$ receptor e esta relação unidimensional entre eles é vista como permissora para a compreensão do que foi dito. Porém, entendemos que explicar a matéria em alto e bom tom de forma clara e objetiva não é suficiente para que o estudante compreenda a mensagem. Os sentidos produzidos por cada aluno a partir da nossa fala são diversos e cabe a nós, professores, 
compreendermos que a história de leitura de cada estudante afeta a construção de sentidos dos mesmos. Por exemplo, uma vez, numa conversa sobre essa questão com uma professora, ela contou o seguinte episódio:

Houve uma prova para o sexto ano, há uns dez anos atrás, na qual perguntei qual o ser vivo que produzia seu próprio alimento e alguns alunos responderam: o ser humano. Ao perguntar por que, disseram que quem fazia a comida na casa deles era a sua mãe.

Diante disto, a Análise de Discurso de linha francesa (AD) entende que não existe essa linearidade na comunicação, pois o emissor e receptor não estão separados e o processo de significação acontece recíproca e simultaneamente. Orlandi (2005) destaca que:

[...] não se trata de transmissão de informação apenas, pois, no funcionamento da linguagem, que põe em relação sujeitos e sentidos afetados pela língua e pela história, temos um complexo processo de constituição desses sujeitos e produção de sentidos e não meramente transmissão de informação. São processos de identificação do sujeito, de argumentação, de subjetivação, de construção da realidade, etc. (ORLANDI, 2005, p.21).

O discurso é definido não como sendo transmissão de informação e sim como o "[...] efeito de sentidos entre interlocutores [...] (ORLANDI, 2005, p.21)", no qual considera que a linguagem é pensada a partir de sujeitos da produção de sentidos. "O dizer tem história. Os sentidos não se esgotam no imediato. Tanto é assim que fazem efeitos diferentes para diferentes interlocutores (ORLANDI, 2005, p. 50)".

Mortimer e Scott (2002) classificam o discurso de interação do professor em dois extremos: o dialógico e o de autoridade.

\begin{abstract}
No primeiro deles, o professor considera o que o estudante tem a dizer do ponto de vista do próprio estudante; mais de uma 'voz' é considerada e há uma interanimação de ideias. Este primeiro tipo de interação constitui uma abordagem comunicativa dialógica. No segundo extremo, o professor considera o que o estudante tem a dizer apenas do ponto de vista do discurso científico escolar que está sendo construído. Este segundo tipo de interação constitui uma abordagem comunicativa de autoridade, na qual apenas uma 'voz' é ouvida e não há interanimação de ideias. Na prática, qualquer interação provavelmente contém aspectos de ambas as funções, dialógica e de autoridade (MORTIMER e SCOTT, 2002, p.287).
\end{abstract}

Sabemos que na rotina da sala de aula, dificilmente conseguiremos somente a abordagem dialógica, porém, sempre que possível, devemos considerar as histórias de leitura e de vida dos estudantes, buscando articular o conhecimento ensinado a questões oriundas do seu dia a dia.

E dos discursos produzidos em sala de aula, emergem inter-relações dos diferentes sujeitos com o mundo, com suas histórias de leitura e com seu contexto sócio-histórico. Analisar os gestos de interpretação, as relações de sentido e as condições de produção são fundamentais para compreender as interações discursivas, bem como explorar sua potencialidade na construção do conhecimento.

Num estudo de Scarinci e Pacca (2007), sobre características da prática docente em sala de aula, as autoras estabeleceram algumas categorias de análise com base em seus dados de pesquisa. A categoria "O professor e as atitudes", foi estabelecida da seguinte forma: "Qual a reação do professor a uma pergunta do aluno quando ele não sabe a resposta a essa pergunta? a) Estuda, junto com o aluno, para descobrir a resposta. b) Estuda e leva a resposta ao aluno. c) Responde algo sem significado". As autoras categorizaram em três respostas as 
atitudes do professor observadas na pesquisa. Penso que é possível incluir também duas outras possíveis atitudes, nas quais já vivenciei enquanto estudante: d) O professor ignora a pergunta do aluno e continua sua aula; e) Fala para o aluno procurar a resposta, por si mesmo, sem orientá-lo.

Estas autoras constataram que o professor ficou inseguro, diante de uma pergunta feita por um estudante, pois ele não tinha argumentos suficientes para respondê-la. Então, resolveu inserir a "definição" do termo central da pergunta, protegendo-o de adentrar num debate que ele não saberia sair (SCARINCI e PACCA, 2007).

Neste mesmo viés, Mendonça e Aguiar Júnior (2015) realizaram uma investigação das interações discursivas a partir de perguntas feitas por alunos em momentos da aula. Os autores relatam seis diferentes estratégias utilizadas pelo professor diante dos questionamentos dos alunos. São elas: 1- responde diretamente a uma questão; 2- repete a questão para a turma; 3- elabora uma nova questão; 4- incentiva o estudante a melhorar sua pergunta; 5- promete resposta futura; 6- ignora a pergunta. Eles ressaltam os fatores que podem elevar a participação discursiva dos estudantes:

[...] a postura dialógica do professor, o incentivo oferecido por ele para que os alunos participem discursivamente da aula, o ambiente receptivo a perguntas e comentários críticos, a importância que o ele dá a cada pergunta, o esforço que ele faz para tentar responder a elas, para o desenvolvimento do discurso científico nesta sala de aula (MENDONÇA e AGUIAR JÚNIOR, 2015, p.7).

Diante disto, um ponto importante para analisarmos é o currículo, que muitas vezes não leva em conta os conhecimentos que os estudantes querem aprender, distanciando assim a teoria da prática. Ademais, ele não prevê, nem dá direcionamentos para o professor a respeito de conteúdos extracurriculares e algumas situações nas quais o docente vai se deparar, mas que não foram previstas ou refletidas a respeito. Assim sendo, é necessário repensarmos a função destes currículos, bem como os conteúdos que nele estão estabelecidos.

[...] os "conteúdos" apresentados pelos currículos representam um "conhecimento" cuja função principal é tornar-se questões de provas ou propostas de trabalhos. Neste sentido, os conteúdos passam a ser respostas a perguntas não formuladas pelos alunos, que eles devem, no entanto, guardar para darem como respostas quando, em provas ou trabalhos, as perguntas lhes forem feitas (SGARBI, 2004, p. 4).

Partindo deste pressuposto de que os conteúdos presentes no currículo são respostas a perguntas que os estudantes não fizeram, quais seriam as perguntas que esses estudantes fariam se o currículo fosse organizado inversamente, isto é, a partir de indagações dos estudantes? Existiriam perguntas mais adequadas para elaborar um planejamento, um currículo?

Sgarbi (2004, p.7) afirma que uma pergunta é considerada certa, ou melhor, pertinente, pelo "[...] fato de ser feita, de expressar o desejo de alguém em saber alguma coisa, independente de o conteúdo da pergunta ser considerado lógico ou não a partir de um pressuposto teórico dado." Desta forma, o autor alega que as respostas instituídas nos currículos não respondem a todas as perguntas e sim a um conjunto de conhecimentos específicos pré- estabelecidos, no qual não corresponde à realidade de todas as pessoas e que possui forte relação com o poder e a hierarquização. $\mathrm{O}$ autor sugere ainda que: "[...] é preciso que as propostas curriculares sejam invadidas pela curiosidade, pelas perguntas que surgem dos conhecimentos que, informalmente, as crianças vão tecendo em suas cabecinhas" (SGARBI, 2004, p. 4). Extrapolamos esta ideia não somente para as crianças, mas 
acreditamos que a curiosidade deve perpassar por toda a Educação Básica, independentemente da idade, pois quando assumimos que aprender é um processo social,

[...] o foco desloca-se para as interações e os procedimentos de ensino e tornam-se fundamentais. O que se diz, como se diz, em que momento e por quê; da mesma forma que, o que se faz, como se faz, em que momento e por quê, afetam profundamente as relações professor-aluno, influenciando diretamente o processo de ensino-aprendizagem. O comportamento do professor e de seus alunos, em sala de aula, expressa suas intenções, crenças, seus valores, sentimentos, desejos que afetam cada participante individualmente (MENDONÇA e AGUIAR JÚNIOR, 2015, p.7).

Uma questão que está diretamente relacionada com o comportamento do professor é a formação inicial em nível superior, já que esta reflete diretamente em suas concepções teóricas e metodológicas, bem como no seu modus operandi. Os cursos de Ciências- especificamente de Química- são potencialmente quantitativos, no qual o currículo, de uma forma geral, dá grande ênfase ao desenvolvimento de habilidades quantitativas, como a efetuação de cálculos e resolução de problemas, em detrimento ao desenvolvimento de habilidades qualitativas, como a escrita (QUEIROZ, 2001). Se o professor, durante seu processo formativo, não se depara com atividades que estimulem a reflexão de situações inusitadas utilizando a criatividade, a curiosidade e a argumentação, tão pouco estas atividades se refletirão em sua prática, pois a tendência é manter-se em situações de segurança que podem ser previstas com facilidade e não buscar o novo e inesperado.

Diante disto, propomos uma prática para o ensino de Química e de forma mais ampla para o ensino de Ciências, que traz alguns direcionamentos às seguintes questões: Como lidar com as perguntas inusitadas feitas pelos estudantes? E como essas questões podem contribuir para a construção do conhecimento científico? É a partir desse questionamento, apoiado nos referenciais apresentados, que apresentamos a seguinte atividade.

\section{A atividade "Não faço a menor ideia!?"}

A tarefa de desafiar os estudantes através da investigação inicia com a elaboração de uma pergunta que nos intriga na qual não temos uma resposta imediata (PONTE et al., 1998). $\mathrm{O}$ trabalho de Ponte e colaboradores baseou-se na observação de uma atividade de investigação matemática em sala de aula. Nesta pesquisa o professor apresentava uma tarefa à turma, acompanhava o desenvolvimento em grupo da investigação e os estudantes apresentavam seus resultados, discutindo posteriormente com toda a turma e com o professor para fazerem um balanço final da investigação. Era o professor que selecionava uma questão desafiante para os alunos investigarem.

Já no presente trabalho, propomos que essas perguntas partam dos próprios estudantes, levando em conta suas demandas, expectativas, além de estimular a curiosidade dos mesmos. A atividade do "Não faço a menor ideia" surgiu de uma conversa entre as autoras no Grupo de Estudos e Pesquisa CoMtextos. Uma das autoras, professora no ensino superior, tinha esta ideia há algum tempo e então decidimos implementar na da educação básica, onde sou professora. A ideia ganhou então cores e formas ao adentrar em sala de aula.

A partir de agora, eu vou contar a minha experiência com esta proposta, que foi iniciada em uma escola pública, de sistema militar, em Juiz de Fora, durante as aulas de Química do $1^{\circ}$ ano do Ensino Médio. Percebi a necessidade de considerar certas perguntas que os estudantes me faziam pelas quais eu não tinha resposta de imediato. Algumas turmas 
eram muito curiosas sobre os diversos assuntos ligados à ciência e isto me motivou a pôr em prática o "Não faço a menor ideia". Atualmente o trabalho também é proposto no Ensino Fundamental de uma escola particular de Juiz de Fora, nas disciplinas de Química e Física.

A atividade é realizada 1 vez por semana e tem duração de aproximadamente 15 minutos. Uma vez por semana, um aluno faz uma pergunta, que será pesquisada por todos para ser discutida na próxima semana. A pergunta deve estar relacionada de alguma forma com o conteúdo que estão estudando, a fim de contribuir na ampliação das ideias sobre aquele conteúdo. Um aluno ou um grupo de alunos ficam responsáveis por trazer um levantamento das respostas obtidas no formato impresso. Os demais podem relatar a pesquisa no caderno ou apenas pesquisar e levar a discussão para a sala. $O$ professor também pesquisa sobre a questão escolhida e ele direciona a discussão (Figura 1). Assim, os alunos que pesquisaram leem as informações que trouxeram e eu, professora, sintetizo e acrescento informações ao que eles leram.

Geralmente neste momento surgem várias outras questões a respeito do tema, que são aproveitadas para a próxima semana do "Não faço a menor ideia".

Figura 1: Esquema da atividade "Não faço a menor ideia"

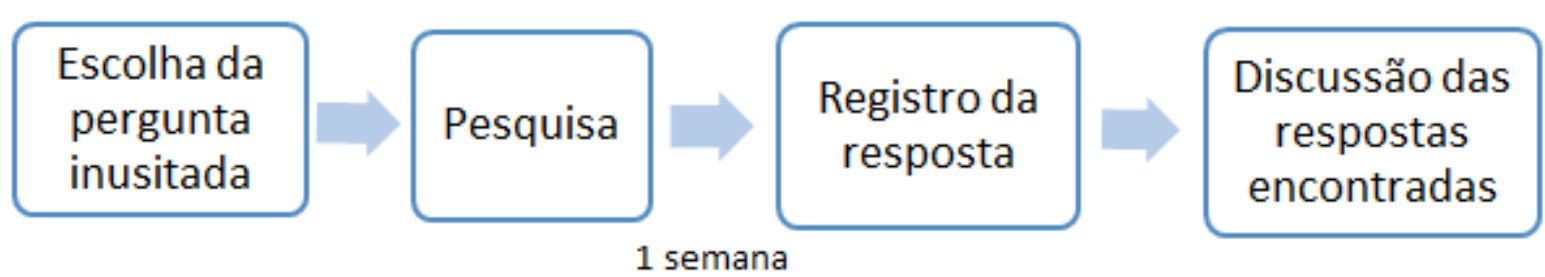

Fonte: elaborado pelas autoras

Alguns exemplos de questões que já foram trabalhadas: "Como funciona o wi-fi?"; "Por que o ouro puro não pode ser usado para fabricar joias?"; "Por que o elemento químico Kuchatovio saiu da Tabela Periódica?"; "Como se formam as auroras boreais?”; Por que um ímã atrai o metal de todos os lados?"; “O que é buraco negro?”... e etc.

Certa vez, um aluno fez a seguinte pergunta: Professora, como se fabrica a pólvora? $\mathrm{Eu}$ disse que eu não tinha uma resposta imediata para dar para ele e propus que a utilizássemos na próxima semana do "Não faço a menor ideia". Todos os estudantes concordaram e se comprometeram a pesquisar sobre o tema durante o decorrer da semana. No dia definido, o próprio aluno que fez a pergunta, trouxe uma resposta impressa que ele encontrou na internet e alguns outros alunos leram também o que pesquisaram. Ao final das leituras, passei no quadro para eles algumas reações que foram mencionadas nas pesquisas e expliquei, de forma mais superficial, o que significavam (como eles estavam estudando modelos atômicos, ainda não tinham requisitos suficientes para adentrar numa discussão de reação química).

Em seguida, este mesmo aluno contou um caso de um acidente com um amigo do pai dele que morreu ao tentar fabricar pólvora caseira. Desta forma, discuti com os alunos os perigos de realizar reações químicas sem os equipamentos e métodos adequados e sem 
orientação de um profissional. O debate foi bastante interessante e permitiu que pudéssemos discutir muito mais que do que a pergunta inicial propunha. Os estudantes- cujos nomes são fictícios para preservar a identidade dos mesmos- afirmam que gostam bastante desta atividade, como podemos observar nos seus relatos:

“"Não faço a menor ideia' é muito interessante, pois usamos dessa forma, para descobrir certas curiosidades que às vezes não sabemos e não dá para colocar como matéria e dessa maneira aprendemos coisas que antes não fazíamos ideia" (João).

"Eu acho uma ideia legal, divertida, que sai um pouco das aulas normais, é uma forma de aprender coisas novas" (Laura).

Esta prática vem se mostrando bastante interessante, pois desafia os estudantes a buscarem informações, pensarem numa questão e seus desdobramentos, bem como elaborarem uma questão pertinente ao tema estudado em sala.

Ao devolver a questão a toda a turma, a professora evidencia a sua expectativa de que os alunos possam dar uma contribuição importante sobre a questão proposta. A constante (re)definição das margens de atuação dos alunos, à medida que a aula decorre, constitui também uma forma de gerir a situação didática vivida na aula (PONTE et al., 1998, p. 19).

\section{CONSIDERAÇÕES FINAIS}

No nosso dia a dia muitas perguntas possuem mais de uma resposta ou diferentes soluções possíveis, porém, na escola, geralmente nos deparamos com perguntas que assumem respostas unívocas e que não geram discussões a respeito. Como formaremos cidadãos críticos e conscientes se os estamos preparando para darem uma única resposta certa frente a questões avaliativas que lhes são propostas? Diante disto, acreditamos que estimular as perguntas (das mais objetivas às mais complexas e inusitadas) é um caminho para lidar com esse engessamento que nos é imposto.

A atividade que propomos neste trabalho, que já vem sendo desenvolvida há mais de um ano em sala de aula, tem se mostrado propulsora para fomentar com os professores de ciências uma importante questão que permeia suas práticas, apresentando uma proposta alternativa para construir conhecimentos científicos partindo do interesse e da realidade dos estudantes. Permite também que o professor se sinta mais seguro quando este se depara com uma pergunta com o qual não sabe responder de imediato, além de proporcionar um ambiente saudável para o estudante expor suas dúvidas e fazer perguntas.

\section{REFERÊNCIAS}

ALMEIDA, L. S. Facilitar a aprendizagem: ajudar aos alunos a aprender e a pensar. Psicol. esc. educ., Campinas, v. 6, n. 2, p. 155-165, 2002.

CANDELA, A. El discurso argumentativo de la ciência em el aula. Encontro sobre teoria e pesquisa em Ensino de Ciências, Belo Horizonte, 1997. 
MENDONÇA, Douglas Henrique; AGUIAR JÚNIOR, Orlando Gomes. Análise das interações discursivas em uma sala de aula de ciências: estratégias do professor frente às perguntas dos estudantes. X ENPEC, Águas de Lindóia- SP, 2015.

MORTIMER, E. F; SCOTT, P. Atividade discursiva nas salas de aula de ciências: uma ferramenta sociocultural para analisar e planejar o ensino. Investigações em Ensino de Ciências - v.7, n.3, p. 283-306, 2002.

ORLANDI, E. P. Análise do discurso: princípios e procedimentos. 6. ed. Campinas: Pontes, 2005.

PONTE, J. P.; OLIVEIRA, H.; BRUNHEIRA, L.; VARANDAS, J. M.; FERREIRA, C. (1998). O trabalho do professor numa aula de investigação matemática. Quadrante, 7(2), 4170.

QUEIROZ, S. L. A linguagem escrita nos cursos de graduação em química. Química Nova, v.24, n.1, 2001, p.143-146.

SCARINCI, Anne Louise; PACCA, Jesuína Lopes de Almeida. Características das práticas docentes em sala de aula - como ocorre a fragmentação da sequência pedagógica? Anais do VI ENPEC, Florianópolis, 2007. Disponível em:

<http://www.nutes.ufrj.br/abrapec/vienpec/CR2/p804.pdf>. Acessado em: 18 de agosto de 2016.

SGARBI, Paulo. Entre perguntas e respostas, conversando com meu filho sobre currículo. $27^{a}$ Reunião Anual da ANPEd, Caxambu-MG, 2004. Disponível em:

<http://27reuniao.anped.org.br/gt12/t1210.pdf>. Acessado em: 18 de agosto de 2016.

Data de Recebimento: 20/06/2017

Data de Aprovação: 20/07/2017 